\title{
Perceptions of Oral Errors and Their Corrective Feedback: Teachers vs. Students
}

\author{
Elżbieta Tomczyk \\ Department of English Studies, Faculty of Pedagogy and Fine Arts, Kalisz, Adam Mickiewicz University, Poznań, \\ Ploland
}

\begin{abstract}
Being interested in the whole process of teaching and learning a language, researchers and linguists have attempted to describe what errors and corrective feedback are, which together form an inevitable and indispensable part of instructed second and foreign language acquisition (Hendrickson, 1987). They have tried to define them in order to help learners and teachers in dealing with deviant forms that occur during speaking activities in the foreign language classroom (Nunan, 1996). Moreover, when it comes to error correction, one should not forget about a range of decisions that need to be taken into account after having noticed an error in a student's utterance (Long, 1977). As a consequence, explaining errors and proposing the ways of rectifying incorrect forms during speaking play a vital role in students' successes in language learning and teachers' practices. The major aim of this paper is to report and compare teachers' and students' perceptions of oral errors and their corrective feedback as an inseparable part of language acquisition. The participants of the study were 43 secondary school teachers and 250 learners of English as a foreign language, who filled out questionnaires and were observed in real-life situations occurring in the language classroom. As regards the decision-making process and corrective feed-back, the analysis of the data revealed both differences and similarities in the opinions of the two groups of respondents in comparison with the actual classroom conditions, which indicate that correcting students' erroneous forms is a complex issue meriting further investigation and consideration.
\end{abstract}

Index Terms - corrective feedback, oral errors, beliefs, perception

\section{INTRODUCTION}

There has been much discussion on errors and their correction in the foreign language classroom because of the fact that the attitudes towards errors of both teachers and students differ, as well as error correction diverge depending on the approaches that are applied. According to James (1998) language is said to be uniquely human, so an error is like-wise distinctive. But how can an error be defined? A typical definition includes the reference to the linguistic form which deviates from the correct one. However, what does it mean 'correct'? The term is very often identified with the native speaker norm (Allwright \& Bailey, 1991) which is, however, controversial because native speakers' utterances vary too much and most of the language teaching takes place in a non-native context by non-native speakers. In order to analyze learner language in a proper perspective, it is crucial to distinguish between errors and mistakes. An error is a deviant form which results from lack of knowledge of a particular form and reflects a learner's current stage in the in-terlanguage development (Corder, 1967; Selinker, 1972). It is an attempt to try something out, even though a learner does not have sufficient knowledge to produce a given form or item correctly. A mistake, however, refers to a learner's temporary inaccuracy (Corder, 1967) and performance problems and takes place when a student is familiar with the rule but an incorrect form appears because of inattention, fatigue, or as a result of a shift from the initial plan or intention during speaking. Mistakes manifest themselves as hesitations, slips of the tongue, random ungrammaticalities and other performance lapses (Brown, 1994). In spite of many attempts of researchers and scientists to set a definition which still remains problematic, generally one can state that an error is the form of foreign language produced by a learner, which reflects his or her contemporary competence and which does not belong to the target language system.

In the process of learning and teaching a language an error has always been regarded as something negative, as a re-sult, both teachers and students have adopted a repressive attitude towards it. Such a belief was supported by behaviourists, such as Skinner (1957) who perceived the process of language learning as a habit formation and an error as an obstacle which should be avoided because it caused the formation of bad habits. A different point of view was presented by Chomsky (1959) who claimed that language learning is not a mechanical process but rather a mental one where learners test some previously formed hypotheses against positive evidence. This cognitive process of rule formation may be modified by negative evidence, that is correction. According to cognitivists a learner has its own language system, called Interlanguage (Selinker, 1972), which signifies a learner's contemporary stage of knowledge of the second language and it represents the continuum of stages that characterizes a learner's progress (Ellis, 1994). From this perspective, errors are the evidence of the development in the language learning process. Error making is stated to be an inevitable and necessary part of language learning (Dulay \& Bart, 1974; Hendrickson, 1987), as it is a sign that the learner develops and assimilates the rules of language. Moreover, errors help teachers to verify what features of 
language cause students learning problems and tell how far towards the goal learners have progressed and, consequently, what is to be acquired (Corder, 1981). A number of errors and the types of them serve not only as indicators of the proficiency level, but they also help teachers in applying appropriate steps to treat learners difficulties, as they are provided with feedback on the effectiveness of teaching materials and techniques adopted and receive information whether they can move on to the next item which is included in the syllabus. Corder $(1967 ; 1981)$ highlights that teachers should not only notice errors but try to understand some psychological reasons for their occurrence as well.

Apart from the distinction between an error and a mistake, deviant forms can be ascribed to various categories de-pending on characteristics that are taken into account. A well-known taxonomy involves the specification of errors in terms of linguistic categories, in terms of the location of an error in the overall system of the target language "based on the linguistic item which is affected by the error" (Dulay et al., 1982; James, 1998, p. 104f). Taking into account this criterion one can distinguish the following types of errors: phonetic, morphological, syntactic, lexical, semantic and pragmatic. In the process of identifying and describing errors, the division between covert and overt errors has been made where the former are said to be unquestionably ungrammatical at the sentence level, whilst the latter are grammatically correct but cannot be interpreted within the context of communication (Corder, 1973). For example, "I'm fine, thanks." is a correct sentence but if it is given as an answer to the question of "How old are you?" it is a covertly committed error. Another criterion in classifying errors which has an influence on providing correction is whether a deviant form impedes communication or not, in other words, whether a sentence is comprehensible or not. Such a distinction has been proposed by Burt and Kiparsky (1974) who defined a global error as the one which affects the interpretation of the whole sentence (examples are: word order, missing or wrongly placed sentence connectors, and syntactic overgeneralizations), and a local error as a type which affects a single element in a sentence. It is important to define an error, its source, a type, since it has a considerable impact on further decisions that a teacher has to make, namely, the decisions concerning corrective feedback.

Generally speaking, error correction is defined as a reaction to a speaker's utterance by someone who has made an assessment that the utterance itself or at least the part of it is linguistically or factually wrong. James (1998) regards cor-rection as the improved version of what the first speaker aimed to say. It must be noted that researchers distinguish the difference between error correction and corrective feedback, however, for the purpose of this article, the author has de-cided to use both terms interchangeably. The notions of feedback and correction are very often presented in terms of evidence, which is the information that learners receive about the target language and their attempts at reproducing it. One can distinguish two main kinds of evidence, namely positive and negative. Positive evidence is the information about what is possible in the language, for example, listening to $\mathrm{BBC}, \mathrm{CNN}$ or lectures gives the positive exposure of language (and this is authentic). In case of a teacher talking in the classroom, the language is modified because of sim-plifications or elaborations. Negative evidence (or feedback) is defined as the information about what is not possible in the language. In naturalistic contexts feedback is the result of negotiation, whilst in the language classroom it is pro-vided by the teacher owing to his or her superior knowledge and the communicative asymmetry that puts the teacher in the position of power (Pawlak, 2004).

The question arises whether error correction is needed and useful in the process of language acquisition. As the issue is rather controversial it has both proponents and opponents. One of the critical opinions is that very often error correc-tion is unreliable, vague and ineffective (Long, 1977). The similar statement is presented by Truscott (1999) who added that there is no proof that corrective feedback is helpful but teachers treat it as something always necessary in the lan-guage classroom. He also claimed that error correction is more of a hindrance rather than a useful tool. Some linguists, including Krashen (1982) have believed that language is acquired unconsciously and learning it formally is of little use in later real life situations, that is why concentrating on formal correction is rather counterproductive. Moreover, it is argued that "error correction puts learners on the defensive and, as a result, they tend to avoid using difficult structures and focus on form rather than meaning" (Pawlak, 2004, p. 47). Nonetheless, there are adherents of providing corrective feedback, including Lyster, Lightbrown and Spada (1999) who disagree with Truscott's paper claiming that correcting students' deviant forms rarely hurts their self-esteem and most of learners expect to receive corrective feedback. Fur-thermore, it should be borne in mind that learners' output is at the same time input for themselves and other students in the classroom, therefore lack of corrective feedback may cause that some hypotheses stay incorrect (Schachter, 1998). Another argument involves the assumption that corrective feedback is indispensable, since some grammatical structures are highly difficult to be acquired by means of positive evidence. Providing feedback may also foster learners' language awareness and the ability to notice gaps in their interlanguage. Consequently, both linguistic consciousness raising and noticing gaps result in learners' modifying their output in constructive and long-lasting ways (Pawlak, 2004).

What makes the issue of providing corrective feedback even more complicated is the fact that it requires a range of quick decisions that a teacher needs to make after having noticed an error in a student's utterance. The first decision concerns the question whether an error should be treated in any way. Certainly, such a choice is dependent on some factors, including the aim of a task, namely, if it is to develop fluency or accuracy, and also the proficiency level of stu-dents. Having already decided that an error should be the subject of treatment, a teacher is supposed to choose from three possible options when to deal with an erroneous item and these are immediate, delayed or postponed correction. In spite of the fact that all of them have some advantages and disadvantages, it has to be remembered that when to correct 
is closely related with the decision of how to do that, meaning explicitly or implicitly. The last choice to be made concerns who is the person to provide corrective treatment. Obviously, it is a teacher who reflects a general assumption of who should be such a person, nevertheless, it can also be a learner himself or herself (self-correction) or other students in the classroom (peer correction).

As it has been stated earlier, the concepts of an error and its corrective feedback is a controversial issue because of complexity it is characterized with. There is no doubt that teachers have to face the ubiquity of errors among learners of the foreign language and the methods that are employed by them depend on their general views concerning errors and the corrective feedback. For this reason, the author of the article decided to conduct the research to find out how errors and their corrections are perceived by teachers and how students, who are always direct recipients of all the de-cisions in the classroom, feel about teachers' error correction practice during speaking activities.

\section{RESEARCH: THE AIM OF THE STUDY}

The current study was undertaken to investigate the perception of errors during speaking activities as well as correc-tive feedback from both teachers' and students' perspective, and to check what techniques are used by teachers in or-der to repair erroneous forms created by their students. The researcher also aimed at exploring the actual decisions that are made in the classroom by the teachers and find some similarities and differences with the previously stated beliefs.

\section{A. Participants}

The research was conducted among students of English as well as teachers from secondary schools and technical colleges where English is taught as a foreign language. No criterion was adopted when selecting schools for data collec-tion, however, the researcher was confined to the schools where the teachers and their students agreed to assist in the study.

Forty three teachers of the secondary schools or technical colleges participated in the study whose teaching expe-rience varied from 2 to 25 years. For 15 of them it was less than 5 years, over half of the teachers had taught for almost 10 years, six teachers had the teaching experience more than 10 years, and the other 5 had been teachers for over 20 years. The majority of the respondents, that is $90.7 \%$, declared to have university degrees where 23 of them $(53.5 \%)$ had the MA degree, and 16 teachers (37.2\%) stated to have the BA degree.

The number of participating students in the research is 250 , which is the manifestation of the students who filled out and returned the questionnaires that were later used to analyse the data. All the respondents were the students of the secondary school level whose experience as the foreign language learners ranged from 2 to 13 years. The number of English lessons students were exposed to varied from 2 to 7 hours a week, where the mode is 3 hours. Surprisingly, the majority of the learners $(60.8 \%)$ declared to have limited contact to English or no contact at all outside the classroom. The rest of the students (39.2\%) had the opportunities to exposure to the target language and provided some examples, which are as follows: the Internet (including English websites as well as chat rooms with foreign language speakers), television, music (the lyrics of English songs), books and magazines, computer games, and journeys to foreign language countries where the medium of communication is English. The most frequent access to the target language outside the classroom included private lessons or classes in language schools. It was measured that 34 students (34, 69\%) who de-clared to have a contact to English outside the classroom, attended additional classes.

\section{B. Instruments}

In order to make the study more comprehensive, the researcher decided to select two methods of data collection, namely: questionnaires and observations. The collected data were subjected to both qualitative and quantitative analysis taking into account the belief that the amalgamation of the qualitative and quantitative approaches can be beneficial when conducting classroom-oriented research (Brumfit \& Mitchel, 1990).

Questionnaires were distributed among the teachers and some of their students in the foreign language classroom. The choice of this introspective instrument aimed at gathering the necessary data which would provide the researcher with the background information about the respondents and their beliefs and expectations concerning the phe-nomenon of corrective feedback during speaking activities. The collected questionnaires supplied the researcher with significant amount of crucial information which turned out to be invaluable when it came to describing and evaluating the repairing processes during a lesson. In order to avoid possible comprehension problems and to prevent potential dis-tortion of the results, the questionnaire was presented to all the subjects in the Polish version. The questionnaires admin-istered to the teachers and students consisted of both open-ended questions where the respondents were supposed to write their own answers and opinions to the given aspects, and closed-ended ones where they selected one or several of the specified answers. The decision to put the two sorts of questions was to obtain as many varied answers as possible, encouraging the subjects to provide their views or propositions the researcher might not have taken into account.

The further step to validate the research was to observe the lessons of the teachers who agreed to the presence of the researcher. Due to the opportunities for the observations, it was possible to verify the views and opinions stated in the questionnaires with the real decisions that the teachers had to make in the language classrooms. During the time of ob-serving the interactive processes in the classroom, the researcher attempted to maintain a low profile and always 
took the seats at the back of the classroom. It must be highlighted that the purpose of the observations was explicated to the students who were also assured that the data would be available to the researcher, but not their teacher or the au-thorities of the school.

\section{Results and Discussion}

One of the objectives of the present study was to investigate the opinions about oral errors which affect the later decisions involving corrective feedback. The collected results of both the teacher's and the students' questionnaires were analysed and compared focusing mostly on similarities and differences between them.

On the basis of the data, the importance of corrective feedback seems to be unquestionable, since the majority of both teachers and students (81.4\% of the teachers and $92.8 \%$ of the learners) agreed that errors have to be corrected. According to the teachers, a learner needs to receive the information of their errors, so that he or she does not commit the same error repeatedly in the future. What is more, corrective feedback helps teachers in controlling students' utter-ances and it also improves the effectiveness of them. It must be highlighted that students should be aware of their erro-neous forms, since in many cases error correction motivates to work on their deviant forms and, as a consequence, make a progress. As a result, the teachers use corrective feedback rather often, namely 55,8\% of them declared to do that frequently. The learners answered similarly to the teachers, stating that the most crucial argument in favour of corrective feedback is that errors have to be eliminated as soon as possible, before the habit-formation takes place and wrong forms become part of the students' interlanguage.

As far as the distinction between global and local errors, which seems to be valuable in the further process of the teacher's decision making involving correction, the research project revealed that over half of the teachers $(65.11 \%)$ al-ways decide to focus on global errors, and 15 of them $(34.88 \%)$ do that frequently. As regards local errors, the teacher's severity seems to be of smaller scale, since most of them $(53.48 \%)$ declared to correct local errors from time to time. All the results concerning the aspect of global and local errors from teachers' perspective are presented in the underlying table (Table 1):

TABLE I.

THE TREATMENT OF GLOB AL AND LOCAL ERRORS AMONG TEACHERS

\begin{tabular}{|l|l|l|}
\hline Frequency of correction & Global errors (\%) & Local errors (\%) \\
\hline Always & 65,11 & 2,32 \\
\hline Often & 34,88 & 20,39 \\
\hline Sometimes & 9,30 & 53,48 \\
\hline Rarely & 2,32 & 30,23 \\
\hline Never & 0 & 0 \\
\hline
\end{tabular}

The students taking part in the study were supposed to decide which of these two types of errors they perceive as the most crucial in the process of providing corrective feedback. Global were chosen by 30,4\%, whilst $69,6 \%$ of students claimed that even local errors which do not impede communication should be treated.

As regards the types of errors, out of the three main sorts of errors (grammatical, pronunciation and lexical ones), grammatical and pronunciation errors tend to be the most important (see Diagram 1). The group of 37 teachers $(86,04 \%)$ and 161 students $(64,4 \%)$ chose pronunciation errors as the most crucial errors to be corrected. However, the other type with great importance are grammatical errors, since 72,09\% of the teachers and 57,6\% of the learners de-cided that they need to be focused on when providing corrective feedback. As regards lexical errors, both the teachers and the students consider them as valid in the process of language learning, however, they are perceived as the least important from all the types mentioned in the questionnaires (the group of $34,88 \%$ of the teachers correct these types of errors, while $39,6 \%$ of the students claim that they should be corrected).

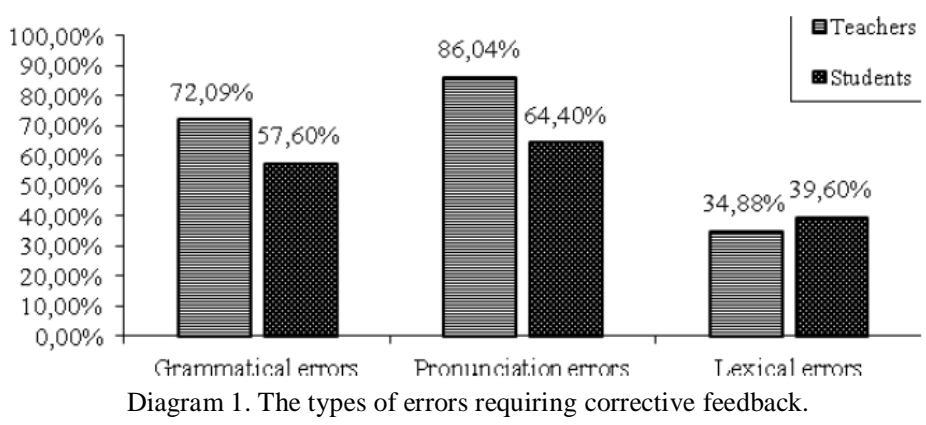

Another corollary of cardinal importance in the process of the teacher's decision making is the question who should provide the correction. The findings are not very revealing, since it is a teacher who is perceived by students as a com-petent, non-erring and ultimate authority $(92,4 \%$ of the learners consider a teacher as the person who is supposed to correct them). It has been proved as in the theoretical part of the thesis that peer correction is not appreciated by the learners (only 4 students out of 250 stated that it the other students who should provide correction), although the 
teachers claim to give opportunities for such correction (36 claim to do that, obviously with different frequency). As far as self-correction is concerned, the teachers state to give a student a chance to correct himself, and the results are: 11 respondents $(25,58 \%)$ always promote self-correction, 27 teachers $(62,79 \%)$ do that frequently, 7 people $(16,27 \%)$ sometimes allow students to correct themselves, and 2 teachers $(4,65 \%)$ declare to promote self-correction rather rarely. On the contrary to the teachers' answers, the students do not seem to prefer self-correction, since only $17,2 \%$ of them would like to have the opportunities for this type of correction.

The decision concerning the time of providing corrective feedback is always the matter of a question, as a result, the respondents were asked to give information about this aspect with a short explanation to the selected option. The re-sults of both groups are shown below (Diagram 2).

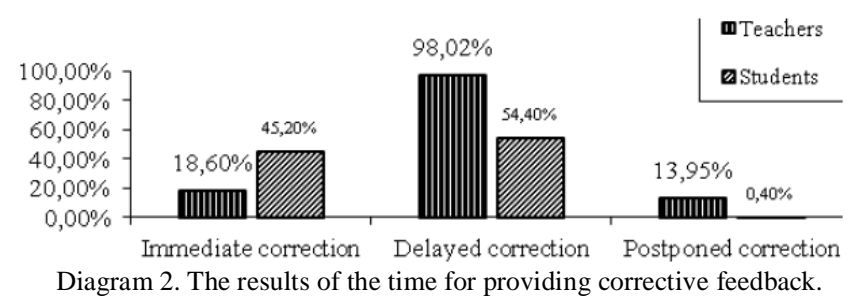

As shown in the Diagram 2, delayed correction is especially favoured by the teachers (98.02\%) who bear in mind that interrupting a student's utterance might have its negative consequences. The result between immediate and delayed correction among students is not as visible as in the teachers' case. The number of adherents of the immediate correction among the students is $45.20 \%$, and $54,40 \%$ of the learners would like the teacher to delay his or her correction, so that the flow of the communication is not disrupted. The reasons why the delayed correction is so much favoured by both groups of respondents is that this kind of correction allows a learner to finish his or her utterance without the interruption for correcting the occurred errors. The students claim that in the case of immediate correction, they feel stressed out and very often forget their initial aim of speaking or answering a particular question in the classroom, as a result, $40,8 \%$ of the students do not like their teacher to correct them during speaking classroom activities. Some of them also stated that immediate correction makes them commit even more errors because of the feeling that they cannot perform in the target language. The group of $18,60 \%$ of the learners declared that the teacher's immediate correction is obtrusive for them, and surprisingly to the author, some even claimed this type of providing correction as ill-mannered.

Due to the observations in the classroom, the researcher may claim that both immediate and delayed corrections were the two most used types of remedial treatment in the foreign language classroom. As regards delayed correction, the teachers made notes of the students' performances and then provided them with the corrective feedback. The other correction that appeared was immediate correction which was particularly used to correct pronunciation errors, and unfortunately, some of the students did not wish to continue and claimed that they forgot what they wanted to convey because of the interruptions. In accordance with the results from the questionnaires, peer-correction was not widely used, in spite of the fact that some of the teachers encouraged their students to use this type of correction.

The researcher included some of the possible options to deal with the noticed errors, which might be undertaken after the previous decisions have been made, namely whether to correct or not, who should provide the correction, when the corrective should take place. Because of the number of the techniques, the similarities and differences are best presented in the Table 2 below:

TABLE II.

THE WAYS OF PROVIDING ERROR REPAIR

\begin{tabular}{|l|l|l|l|l|}
\hline The ways of providing corrective feedback & Teachers & Students \\
\cline { 2 - 5 } & Number & $\%$ & Number & $\%$ \\
\hline Indicating of an error and correcting it & 18 & 41,86 & 85 & 34 \\
\hline $\begin{array}{l}\text { Indicating of an error by means of gestures and } \\
\text { waiting for a student to correct it }\end{array}$ & 25 & 58,13 & 83 & 33,2 \\
\hline $\begin{array}{l}\text { Indicating of an error by repeating it and waiting } \\
\text { for a student to correct it }\end{array}$ & 21 & 48,83 & 74 & 29,6 \\
\hline $\begin{array}{l}\text { Indicating of an error by asking a question and } \\
\text { waiting for a student to correct it }\end{array}$ & 16 & 37,20 & 59 & 23,6 \\
\hline $\begin{array}{l}\text { Indicating of an error by using gestures, repeating } \\
\text { the error, or asking a question and waiting for other } \\
\text { students to correct it }\end{array}$ & 6 & 13,95 & 16 & 6,4 \\
\hline $\begin{array}{l}\text { Correcting an error and reintroducing a particular } \\
\text { item (e.g. a grammar rule) }\end{array}$ & 22 & 46,51 & 203 & 81,2 \\
\hline $\begin{array}{l}\text { Indicating of an error and waiting for a student to } \\
\text { correct it and give an explanation }\end{array}$ & 14 & 32,55 & 64 & 25,6 \\
\hline $\begin{array}{l}\text { indicating of an error and waiting for other } \\
\text { students to correct it and give an explanation }\end{array}$ & 15 & 34,88 & 25 & 10 \\
\hline $\begin{array}{l}\text { Looking for an explanation of an error and ways to } \\
\text { correct it in pairs or groups }\end{array}$ & 6 & 13,95 & 41 & 16,4 \\
\hline Others & 0 & 0 & 2 & 0,8 \\
\hline
\end{tabular}


As the Table 2 shows, the most common technique used by the teachers is indicating the noticed error by means of gestures and asking for correction by the students who committed a given error. Another technique preferred by the teachers is indicating an error using repetition with a rising tone and waiting for the student who has made the error to correct it. The way of correcting an error which the teachers chose in the number of $46,51 \%$, but the most favoured by the students $(81,2 \%)$ is the indication of an error with the explanation of a particular language aspect which was used incorrectly. On the basis of the observations, such a technique is usually used concerning a grammatical aspect which needs to be reminded to the students because of occurring errors. The most common techniques used by the teachers were those where the learner was supposed to correct himself or herself, the teachers gave enough time for such correc-tion, and also encouraged the peers in the classroom to help in finding the solution to the given problem. The observed teachers very often used explicit forms of indicating that there was an error in the utterance, for instance, they used ris-ing intonation, or they showed it by means of gestures or mimes.

The last aspect to be measured was the learner's reaction to the corrective feedback they received from their teach-ers. The researcher proposed four most possible reactions that the teacher may encounter after having decided to pro-vide correction. Surprisingly, the study revealed that the students expect and even want to have their errors corrected (44\% of the students admitted to be satisfied when the teacher corrects their ill-formed utterances). The second common reaction is the students' becoming nervous and angry because of committing an error or because the teacher provides the feedback generally. From the teacher's point of view, the results are not as explicit as in the student's case, since 34,53\% of the teachers perceive students as rather being indifferent to error correction, the group of 32,55\% of the teachers claim that their students react rather with anger or irritation when being corrected, and 30,23\% of them state that students are satisfied with the corrective feedback they receive. The other propositions which the teachers suggested, but were not included in the questionnaire are that students sometimes ponder upon the errors they made, or they get a sort of enlightenment after having received correction that they know the erroneous form or the structure. All the results involving the students' reaction to corrective feedback are presented in the diagram below (Diagram 3 ).

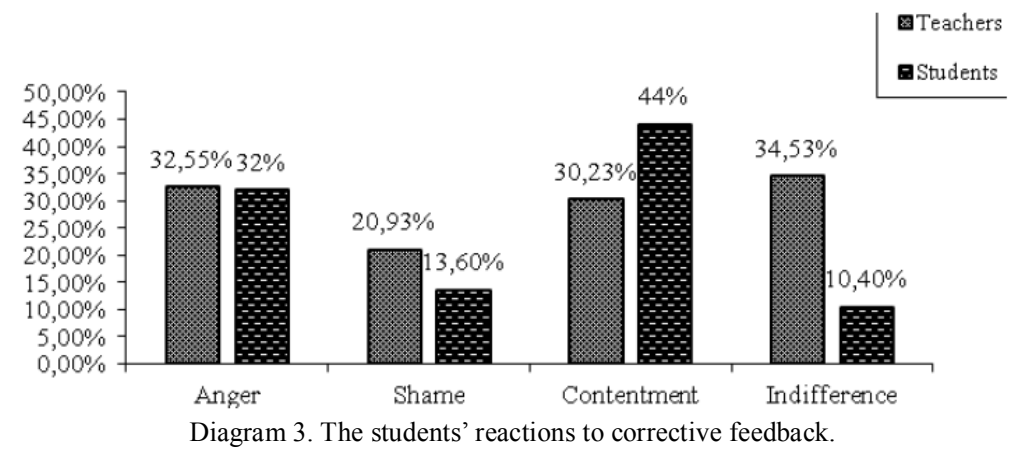

\section{Limitations of the Study}

In spite of making efforts to achieve as comprehensive research as it was possible, the study, however, has some limitations. The main limitation of the study is that the researcher was confined to do the research only in the schools where the principals agreed to take part in the study. Another difficulty that the researcher encountered was that many teachers did not want to fill in the questionnaire, as a result, a number of this questionnaire is not as high as it was pre-viously expected. What is more, many teachers refused the researcher to observe and their lessons.

As regards the questionnaires, it seems to be very likely that some of the respondents may not have been reliable be-cause of the unwillingness to admit to the real behaviours and preferences that would present them in an unfavourable light. The questionnaire also included some open-ended questions to obtain as much information as possible from both the teachers and the students, however, it proved to be the mistaken assumption, since in some cases the answers were very brief or there were no answers at all.

Although the research contains the limitations, the researcher has attempted to conclude and suggest some peda-gogical implications based on her findings.

\section{E. Pedagogical Implications}

As can be seen from the analysis, corrective feedback is an important part of the foreign language learning, since it considerably increases the accuracy of learner output. Obviously, the amount of corrective feedback should be adapted to the objective of the lesson, the activity and the needs of learners. If the objective is to develop accuracy, then, of course, corrective feedback is necessary. In this case, one may follow such an order: allow the students to correct himself or herself first, then in the case when it does not work, the teacher may allow for the correction from peers, and finally, if no one knows how to repair the erroneous form, the teacher can give correction. It may seem time-consuming at first sight, however, it helps to reduce the reliance on the teacher and at the same time, increase student autonomy. If the activity focuses on fluency, correction is not as frequent as in the case of the activities developing accuracy, since constant interruption of students' utterances may be perceived as disruptive or even irritating, especially when errors do 
not hamper the meaning of communication. It is worth mentioning that certain amount of corrective feedback even during communication-focused activities might be indispensable, as it improves the quality of an utterance.

As regards the time of providing corrective feedback, teachers may think that it is better not to correct immediately and frequently, but students may assume that their teacher is not qualified enough to correct errors, or that teachers do not want or care of giving feedback. What is more, as noted in the analysis of the research, teachers prefer to provide delayed correction, which unfortunately has some drawbacks. Although, it is less disruptive and irritating than immedi-ate correction, it is more effective to give corrective feedback after erroneous forms have appeared, because the processing mechanisms of students are then more likely to be activated.

Self-correction is extremely important, since it indicates students' active engagement in the process of language learning. Such an active engagement appears when negotiating a form, or when a student is supposed to react or re-spond to the teacher's feedback, and moreover, when the teacher does not give the correct form, but rather provides some sort of hints, a learner is forced to reformulate his or her erroneous utterance. Consequently, one may even con-clude that the least effective technique for correcting students' error incorrect language use is to simply give them an-swer.

In order to rectify both teachers' and students' opposing expectations involving the correction of errors, mistakes and attempts, one should correct them in a positive manner, assuring that any kind of errors is the inevitable part of the foreign language learning. Positive attitude towards the students' mistakes makes students feel more comfortable and confident that they will manage to reduce their erroneous forms in the later process of language learning.

\section{CONCLUSIONS}

Learning a language involves testing out hypotheses about the system, as a result, some of the attempts might be er-roneous. Since errors form the inevitable part of a language, there might be various views concerning them. Some teachers regard errors as failures in teaching particular language aspects, and students perceive them as failures to ac-quire what they are supposed to know. However, errors might also be accepted as an indication of the learning taking place in a learner. The author has been especially interested in investigating the distinctions in opinions between teach-ers and students, and also in comparing their views declared in the questionnaires with the real-life situations occurring in the language classroom. In order to get a comprehensive picture of the aspects under investigation, a non-interventionist approach was adopted and the two different instruments were employed to collect the data.

The quantitative and qualitative analysis demonstrated that speaking in the classroom is perceived as the op-portunity to make errors, that is why so many students hesitate form taking part in the communicative activities. The study makes it clear that corrective feedback is considered to be a crucial part in the language learning, and it is even expected by most students. In addition, the majority of both teachers and learners declare grammatical and pronunciation errors as the ones which seem to be the most crucial as far as error correction is concerned. The findings also reveal that it is a teacher who is regarded as a competent, non-erring and ultimate authority, as a result, he or she is supposed to provide corrective feedback whenever deviant forms occur. Although peer correction and self-correction have many benefits and the majority of teachers declare to promote these types of correction in the classroom, the students seem not to appreciate them and they expect their teachers to rectify what they do not know. It has also been proved that contrary to immediate correction, which is usually regarded as disruptive or even irritating, delayed correction is used the most frequently by teachers, in spite of the fact that it is not as beneficial as it might be seen, since learners' processing mechanisms are less likely to be activated. Among many techniques that might be used in providing corrective feedback, teachers tend to use explicit forms of indicating the appearance of errors, for instance by means of gestures and mimes, or by using a rising tone. From students' perspective, the best option on giving corrective feedback is not only indicating that a student has committed an error, but also reintroducing rules or a definition for the wrongly used item. The study demonstrates that students might react to corrective feedback in a number of ways, however, the findings reveal that learners usually feel content when they receive corrective feedback, which prevents them from committing the same errors in the future.

Having considered the above comments, teachers should always concentrate on the purpose of the activity which frequently has a considerable impact on the decision whether to correct an error or not, and how much of corrective feedback should be provided to students. The activity might also influence the decision concerning when it is ap-propriate to correct the deviant forms. What is more, the neglected self-correction should be promoted among learners, since students are actively engaged in the process of language learning. It should not be forgotten that it is always beneficial to correct students' errors in a positive manner and assure them that due to the wrong forms, the correct ones will be better noticed and remembered in the further processes of learning a language.

\section{REFERENCES}

[1] Allwright, D. and Kathleen M. Bailey. (1991). Focusing on Language Classroom. London: Cambridge University Press.

[2] Brown, H. Douglas. (1994). Principles of Language and Teaching. New York: Prentice Hall Regents.

[3] Burt, M. and Kiparsky, C. (1972). The Gooficon: A Repair Manual for English. Rowley, Mass.: Newbury House.

[4] Chomsky, N. (1959). Review of Verbal behaviour by B.F. Skinner. Language 35, 26-58.

[5] Corder, S. P. (1967). The Significance of Learners' Errors. International Review of Applied Linguistics 5, 161-170. 
[6] Corder, S. P. (1973). Introducing Applied Linguistics. London: Penguin Books Ltd.

[7] Corder, S. P. (1981). Error Analysis and Interlanguage. Oxford: Oxford University Press.

[8] Dulay, H., and Burt, M. (1974). Errors and strategies in child second language acquisition. TESOL Quarterly, 8.1, 129-136.

[9] Ellis, R. (1994). The Study of Second Language Acquisition. Oxford: Oxford University Press.

[10] Hendrickson, J. (1987). Error Correction in Foreign Language Teaching: Recent Theory, Research, and Practice. Modern Lan-guage Journal 62, 387-398.

[11] James, Carl. (1998). Errors in Language Learning and Use. New York: Longman.

[12] Krashen, S. D. (1982). Principles and Practice in Second Language Acquisition. Oxford: Pergamon.

[13] Lyster, R., Lighbown, P. M. and Spada, N. (1999). A response to Truscott's 'What's wrong with oral grammar correction'. The Canadian Modern Language Review 55, 457-467.

[14] Long, M. (1977). Teacher feedback on learner error. Mapping cognitions. In Brown, H. D., Yorio C. and Cymes, R. (eds). (1977), Teaching and learning English as a second language: Trends in research and practice. Washington, DC: TESOL, 278-93.

[15] Pawlak, M. (2004). Describing and Researching Interactive Processes in the Foreign Language Classroom. Konin: Państwowa Wyższa Szkoła Zawodowa.

[16] Schachter, J. (1988). Second language acquisition and its relationship to Universal Grammar. Applied Linguistics 9, $219-235$.

[17] Selinker, L. (1972). Interlanguage. International Review of Applied Linguistics 10, 209-230.

[18] Skinner, B. (1957). Verbal Behaviour. New York: Appleton-Century-Crofts.

[19] Truscott, J. (1999). What's wrong with oral grammar Correction. The Canadian Modern Language Review 55, 437-456.

Elżbieta Tomczyk is a lecturer at the English Department of the Faculty of Pedagogy and Fine Arts of Adam Mickiewicz University in Kalisz, and a teacher of one of the high schools in Kalisz. Her interests include interactive processes in the foreign language classroom, corrective feedback, communication strategies and learner autonomy. 